\title{
The genetic basis of severe combined immunodeficiency and its variants
}

\author{
This article was published in the following Dove Press journal: \\ The Application of Clinical Genetics \\ 6 August 2012 \\ Number of times this article has been viewed
}

\section{Diana Tasher ${ }^{1,2}$ \\ Ilan Dalal ${ }^{1,2}$}

'The Pediatric Infectious and Immunology Unit, E Wolfson Medical Center, Holon, Israel; ${ }^{2}$ The Sackler School of Medicine, Tel Aviv University, Tel Aviv, Israel
Correspondence: Ilan Dalal

Pediatric Infectious and Immunology Unit, E Wolfson Medical Center, POB 5,

Holon 58100, Israel

Tel +97235028302

Fax +9723 5028I64

Email ilandalal@hotmail.com
Abstract: Severe combined immunodeficiency (SCID) syndromes are characterized by a block in T lymphocyte differentiation that is variably associated with abnormal development of other lymphocyte lineages (B and/or natural killer [NK] cells), leading to death early in life unless treated urgently by hematopoietic stem cell transplant. SCID comprises genotypically and phenotypically heterogeneous conditions, of which the genetic basis for approximately $85 \%$ of the underlying immunologic defects have been recently elucidated. A major obstacle in deciphering the pathogenesis of SCID syndromes is that different mutations in a single gene may give rise to distinct clinical conditions and that a similar clinical phenotype can result from mutations in different genes. Mutation analysis is now an important component of the complete evaluation of a patient with SCID since it has a dramatic impact on many aspects of this potentially lifethreatening disease such as genetic counseling, prenatal diagnosis, modalities of treatment, and, eventually, prognosis. Dr Robert Good, one of the founders of modern immunology, described the SCID syndrome as "experiments of nature." By understanding the cellular and genetic basis of these immunodeficiency diseases and, eventually, normal immunity, we optimize the "bedside to research laboratory and back again" approach to medicine.

Keywords: severe combined immune deficiency, molecular defects, lymphocytes

Human severe combined immunodeficiency (SCID) comprises a group of genotypically and phenotypically heterogeneous diseases. The clinical presentation usually includes severe, recurrent, and potentially lethal infections early in infancy such as chronic diarrhea, failure to thrive, lymphopenia (particularly of T lymphocytes) with profound abnormalities of cell-mediated immunity, and antibody deficiency. Skin rashes might reflect graft-versus-host disease caused by maternal T-cell engraftment in infants with SCID or tissue damage caused by the infiltration of activated, autologous $\mathrm{T}$ lymphocytes, as is typically seen in Omenn syndrome (OS). In addition, some forms of SCID are associated with distinctive features in other systems. ${ }^{1}$

SCID is a syndrome caused by mutations in different genes whose products are crucial for the development and function of both $\mathrm{T}$ and $\mathrm{B}$ cells. In some cases, the molecular defect prevents only T-cell function, while B cells are normal. Natural killer (NK) cells, a lymphocyte subset exhibiting cytotoxic activities, develop via a pathway that is distinct from $B$ and $T$ cells. NK cells are present in approximately $50 \%$ of patients with SCID, and provide a degree of protection against bacterial and viral infections in these patients, and, ultimately, a better prognosis. 
SCID immunophenotypes can be classified according to the presence (T-B+SCID) or absence (T-B-SCID) of $\mathrm{B}$ cells in the peripheral blood. Both main groups of SCID include forms with or without NK lymphocytes.

SCID can also be categorized based on the cellular function of the protein that is encoded by the defective gene. The five functional categories include proteins involved in cytokine signaling, antigen presentation, $\mathrm{V}(\mathrm{D}) \mathrm{J}$ recombination, T-cell receptor (TCR) signaling, and basic cellular functions.

SCID syndromes have a prevalence of approximately 1:50,000 live births and are more common in male subjects, reflecting the overrepresentation of X-linked SCID (XL-SCID), the most common worldwide form $(-50 \%)$ of SCID in human subjects. ${ }^{1-3}$

However, in cultures in which consanguineous marriage is common, the incidence of autosomal recessive (AR) SCID is higher than has been previously reported. ${ }^{4,5}$

Gene defects are present in approximately $85 \%$ of SCID cases. ${ }^{1}$ Thus, mutation analysis in the characterization of SCID is now an important component of the complete evaluation of a patient, particularly as affected genes associated with this group of diseases continue to increase. In addition, it has a dramatic impact on many aspects of this potentially lifethreatening disease such as genetic counseling, prenatal diagnosis, modalities of treatment, and, eventually, prognosis.

\section{Normal T-cell development and activation}

Before discussing the different types of SCID phenotypes, one should describe the normal steps involved in T-cell development, maturation, differentiation, and activation. Each step in the normal process that generates normal, functional $\mathrm{T}$ cells is genetically controlled by many structural and regulatory genes, and, therefore, the potential for genetic defects resulting in an abnormal number or function of $\mathrm{T}$ cells - and subsequently, SCID phenotype - is great.

Pluripotential hematopoietic stem cells develop into lymphoid stem cells, which differentiate into T, B, or NK cells depending on the organs or tissues to which these stem cells migrate. T-cell progenitors occur in the embryonic thymus as early as 8 weeks of gestation and, by the age of 10 weeks, $25 \%$ of thymocytes bear the mature, specific T-cell receptor (TCR). TCRs consist of two chains ( $\alpha$ and $\beta$ ) that are coexpressed on the cell surface with CD3 - a multichain signaling complex of five polypeptides: $\gamma, \delta, \varepsilon, \zeta$, and $\eta$. Together, the TCR and the CD3 molecule form the TCR complex. This complex also includes tyrosine phosphatase CD45, which is found on all hematopoietic cells and is essential for the normal maturation of T cells. Early development of TCR in the thymus requires the expression of specific markers such as CD1, CD2, and interleukin 2 receptor (IL-2R) molecules, which serve critical receptorligand functions during the early stages of ontogeny. The next step involves the lymphoid-specific recombinase activating genes $(R A G) 1$ and $R A G 2$, which are responsible for the $\mathrm{V}(\mathrm{D}) \mathrm{J}$ rearrangement process, and are critical for the normal development of TCRs. As immature cortical thymocytes begin to express TCRs, they move through the processes of positive and negative selection. Mature $\mathrm{T}$ cells that survive positive selection either express CD4 and are restricted to interacting only with self class II molecules or express CD8 and are restricted to interacting with self class I human histocompatibility leukocyte antigens (HLAs). The purpose of negative selection is to remove autoreactive $\mathrm{T}$ cells and, subsequently, by the end of the process, $97 \%$ of all cortical thymocytes die. During negative selection, mature single positive T cells emigrate from the thymus to secondary lymphoid organs such as the spleen, lymph nodes, tonsils, and appendix at 12 weeks of embryonic life. Immune cell interaction is crucial for the adequate response and activation of $\mathrm{T}$ cells, since TCRs can only recognize processed antigenic peptides, presented to it by antigen-presenting cells (APCs) such as B cells, macrophages, and dendritic cells, in the context of class I or II HLA molecules. Normal activation of CD4 $\mathrm{T}$ cells by $\mathrm{B}$ cells requires a transient expression of $\mathrm{CD} 40$ ligand molecules on the surface of CD4 T cells, which bind to CD40 molecules on B cells. The TCR then interacts with the peptide-bearing HLA molecule and, through the multichain, CD3 signaling complex, sends a signal to produce cytokines, ultimately resulting in T-cell activation and proliferation. The most important cytokine involved in the activation and proliferation of T cells is IL-2, which binds to its high affinity, multi-chain $(\alpha, \beta, \gamma)$ receptor; namely, IL-2R.

Activation of the TCR complex results in the following activation events: (1) Production of lipid mediators such as inositol triphosphate and diacylglycerol and activation of protein kinase C. (2) Phosphorylation and activation of tyrosine kinases such as Lck and ZAP-70. (3) Elevation of intracellular calcium levels. All these activation events convey messages to the cell nucleus resulting in the normal functioning of T cells. ${ }^{6,7}$

Although it is more appropriate to refer to SCID syndromes according to the specific molecular defect (once it has been identified), phenotypic classification is still viewed as a simpler, more useful, and more intuitive approach. Thus, we decided to take this approach in order to classify the different types of SCID (Table 1). However, some forms 
Table I Classification of SCID syndromes based on immunophenotype

\begin{tabular}{|c|c|c|c|c|}
\hline & Inheritance & $\begin{array}{l}\text { Phenotype } \\
\text { MIM number }\end{array}$ & $\begin{array}{l}\text { Gene/locus } \\
\text { MIM number }\end{array}$ & Specific manifestations \\
\hline \multicolumn{5}{|l|}{ T-B-NK- } \\
\hline $\begin{array}{l}\text { Adenosine deaminase } \\
(A D A) \text { deficiency }\end{array}$ & AR & 102700 & 608958 & $\begin{array}{l}\text { Costochondral junction flaring, neurological } \\
\text { features, hearing impairment, liver injury } \\
\text { May present with Omenn syndrome }\end{array}$ \\
\hline Reticular dysgenesis & AR & 267500 & 103020 & Profound neutropenia, deafness \\
\hline \multicolumn{5}{|l|}{ T-B-NK+ } \\
\hline RAGI/2 deficiency & AR & 601457 & 179615,179616 & $\begin{array}{l}\text { May present with Omenn syndrome. } \\
\text { Hypomorphic mutations have been associated } \\
\text { with a granuloma formation, } \\
\text { and EBV-related lymphoma }\end{array}$ \\
\hline $\begin{array}{l}\text { DCLREIC (Artemis) } \\
\text { deficiency }\end{array}$ & AR & 602450 & 605988 & $\begin{array}{l}\text { Radiation sensitivity. May present with } \\
\text { Omenn syndrome }\end{array}$ \\
\hline $\begin{array}{l}\text { DNA-PKcs deficiency } \\
\mathbf{T - B + N K}-\end{array}$ & AR & & 600899 & Radiation sensitivity \\
\hline $\begin{array}{l}\text { Common gamma chain } \\
(\gamma c) \text { deficiency }\end{array}$ & $X \mathrm{~L}$ & 300400 & 308380 & $\begin{array}{l}\text { Growth failure. May present with } \\
\text { Omenn syndrome or polymorphous } \\
\text { lymphoproliferative disorder }\end{array}$ \\
\hline JAK3 deficiency & $A R$ & 600802 & 600173 & \\
\hline T-B+NK+ & & & & \\
\hline IL7R $\alpha$ deficiency & $A R$ & 600802 & $|4666|$ & May present with Omenn syndrome. \\
\hline Coronin-I A deficiency & AR & & 605000 & Detectable thymus \\
\hline CD45 deficiency & AR & 202500 & 151460 & Normal $\gamma / \delta$ T cells \\
\hline $\begin{array}{l}\mathrm{CD} 3 \delta / \mathrm{CD} 3 \varepsilon / \mathrm{CD} 3 \zeta \\
\text { deficiency }\end{array}$ & AR & 608971 & $\begin{array}{l}\text { I86790, } 186830 \\
186780\end{array}$ & $\begin{array}{l}\text { No } \gamma / \delta \text { T cells. Autoimmune manifestations } \\
\text { are common }\end{array}$ \\
\hline
\end{tabular}

Abbreviations: $S C I D$, severe combined immune deficiencies; $X L, X$-linked inheritance; $A R$, autosomal recessive inheritance; RAG, recombination activating gene; $D C L R E I C$, DNA crosslink repair IC; DNA-PKcs, DNA protein kinase catalytic subunit; JAK3, Janus activating kinase 3; IL7R $\alpha$, IL-7 receptor $\alpha$-chain; EBV, Epstein-Barr virus.

of SCID do not fit into this classification and, therefore, we will use the alternative approach involving cellular function for characterization of these forms (Table 2).

\section{T-B-NK- SCID}

The two identified T-B-NK- SCID forms are adenosine deaminase $(A D A)$ deficiency and reticular dysgenesis (RD). Impaired survival of lymphocyte precursors is observed in both forms.

\section{ADA deficiency}

With an incidence of 1 in 200,000 live births, ADA deficiency accounts for approximately one-third of all cases of AR SCID and approximately $15 \%$ of all cases of SCID. ADA deficiency is caused by mutations in the $A D A$ gene at $20 \mathrm{q} 13.11 .^{8} \mathrm{ADA}$ is an enzyme of the purine salvage pathway that mediates conversion of adenosine (and deoxyadenosine) to inosine (and deoxyinosine). In the absence of functional ADA, there is an intracellular accumulation of the phosphorylated metabolites of adenosine and deoxyadenosine. These products are toxic to lymphoid precursors in the bone marrow and thymus. Approximately $90 \%$ of ADA-deficient individuals have a classic severe SCID phenotype and they develop severe infections in the first months of life. Most of the remainder has a "delayed" or "late onset" form that presents in late infancy or early childhood. The wide spectrum of the ADA-deficiency phenotype is largely related to the variability in genetic mutations. Clinical manifestations of ADA deficiency extend beyond the immune system (deafness, behavioral problems, cognitive deficits, gait abnormalities, costochondral abnormalities, and liver toxicity), reflecting the fact that ADA is a housekeeping enzyme. ${ }^{7,8}$

The definitive treatment of choice is hematopoietic stem cell (HSC) transplantation from an HLA identical sibling or other appropriate donor such as one who is unrelated. Enzyme replacement therapy with polyethylene glycol-ADA (PEG-ADA) is an effective, alternative therapeutic approach in some patients without an appropriate donor. There is a lack of data regarding the effect of PEG-ADA treatment on neurologic abnormalities. ${ }^{9}$ ADA SCID was the first human disease treated by gene therapy.

\section{Reticular dysgenesis}

This form is one of the rarest and most severe types of SCID. Severe infections occur earlier than in other forms of SCID due to profound neutropenia, in addition to markedly decreased $\mathrm{T}$ and NK cells. B cells are absent to low normal. In addition, patients with $\mathrm{RD}$ also have sensorineural deafness. ${ }^{10}$ 
Table 2 Classification of SCID variants based on normal T-cell development

\begin{tabular}{|c|c|c|c|c|}
\hline & Inheritance & $\begin{array}{l}\text { Phenotype } \\
\text { MIM number }\end{array}$ & $\begin{array}{l}\text { Gene/locus } \\
\text { MIM number }\end{array}$ & Specific manifestations \\
\hline DNA ligase IV deficiency & $A R$ & 606593 & 601837 & $\begin{array}{l}\text { Microcephaly, developmental delay, facial } \\
\text { dysmorphism, radiation sensitivity. May present with } \\
\text { Omenn syndrome or with a delayed clinical onset }\end{array}$ \\
\hline Cernunnos deficiency & AR & 611291 & 611290 & $\begin{array}{l}\text { Microcephaly, developmental delay, in utero growth } \\
\text { retardation, radiation sensitivity }\end{array}$ \\
\hline CD3 $\gamma$ deficiency & AR & & 186740 & May present with a benign course \\
\hline MHC class I deficiency & AR & 604571 & $\begin{array}{l}170260,17026 \mid \\
601962\end{array}$ & Necrotizing granulomatous skin lesions \\
\hline CD8 deficiency & AR & 608957 & 186910 & \\
\hline MHC class II deficiency & AR & 209920 & $\begin{array}{l}600005,601863 \\
601861,603200\end{array}$ & \\
\hline $\begin{array}{l}\text { Interleukin-2 receptor alpha } \\
\text { chain (CD25) deficiency }\end{array}$ & AR & 606367 & 147730 & $\begin{array}{l}\text { Lymphocytic infiltration of tissues (lung, liver, gut, and } \\
\text { bone), autoimmunity (may resemble IPEX syndrome) }\end{array}$ \\
\hline p56lck deficiency & AR & & 153390 & \\
\hline ZAP-70 deficiency & AR & & 176947 & \\
\hline $\mathrm{Ca}^{++}$channel deficiency & AR & $\begin{array}{l}612782 \\
612783\end{array}$ & $\begin{array}{l}610277 \\
605921\end{array}$ & $\begin{array}{l}\text { Anhydrotic ectodermic dysplasia, nonprogressive } \\
\text { myopathy, abnormalities in dental enamel. Unique } \\
\text { features of STIMI deficiency: autoimmunity and } \\
\text { partial iris hypoplasia }\end{array}$ \\
\hline $\begin{array}{l}\text { Signal transducer and } \\
\text { activator of transcription } \\
5 \mathrm{~b}(\text { STAT5b) deficiency }\end{array}$ & AR & 245590 & 604260 & $\begin{array}{l}\text { Growth-hormone insensitive dwarfism, dysmorphic } \\
\text { features, eczema, and autoimmunity }\end{array}$ \\
\hline $\begin{array}{l}\text { Winged-helix nude } \\
(\text { FOXNI) deficiency }\end{array}$ & AR & 601705 & 600838 & $\begin{array}{l}\text { Congenital alopecia, and nail dystrophy, abnormal } \\
\text { thymic epithelium }\end{array}$ \\
\hline $\begin{array}{l}\text { Purine nucleoside } \\
\text { phosphorylase deficiency } \\
\text { (PNP) }\end{array}$ & $A R$ & 613179 & 164050 & $\begin{array}{l}\text { Autoimmune hemolytic anemia, neurological } \\
\text { impairment, and neoplasia }\end{array}$ \\
\hline CD40 ligand deficiency & $X L$ & 308230 & 300386 & $\begin{array}{l}\text { Neutropenia, thrombocytopenia; hemolytic anemia, } \\
\text { biliary tract and liver disease, lymphoproliferative } \\
\text { disease, and increased rates of malignancy }\end{array}$ \\
\hline CD40 deficiency & AR & 606843 & 109535 & $\begin{array}{l}\text { Neutropenia, gastrointestinal and liver/biliary tract } \\
\text { disease }\end{array}$ \\
\hline Itk deficiency & AR & 613011 & 186973 & EBV- associated lymphoproliferation \\
\hline $\begin{array}{l}\text { Dedicator of cytokinesis } 8 \\
\text { (DOCK8) deficiency }\end{array}$ & AR & 243700 & 611432 & $\begin{array}{l}\text { Extensive cutaneous viral and bacterial infections, } \\
\text { susceptibility to cancer, hypereosinophilia, severe } \\
\text { atopy, low NK cells }\end{array}$ \\
\hline
\end{tabular}

Abbreviations: SCID, severe combined immune deficiencies; XL, X-linked inheritance; AR, autosomal recessive inheritance; NK, natural killer cells; MHC, major histocompatibility complex; IPEX, immune dysregulation polyendocrinopathy enteropathy (X-linked); Ick, lymphocyte-specific protein tyrosine kinase; ZAP70, zeta chainassociated 70-kDa protein kinase; FOXNI, forkhead box protein NI; Itk, IL-2-inducible T-cell kinase; EBV, Epstein-Barr virus.

This AR SCID is caused by mutations in the mitochondrial adenylate kinase (AK) 2 gene. This enzyme regulates levels of adenosine diphosphate. AK2 deficiency results in increased apoptosis of myeloid and lymphoid precursors. ${ }^{10}$

\section{$\mathbf{T}-\mathbf{B}-\mathbf{N K}+\mathbf{S C I D}$}

All the known causes for T-B-NK+ SCID syndromes involve defects in $\mathrm{V}(\mathrm{D}) \mathrm{J}$ recombination. This form of AR SCID phenotype accounts for $20 \%$ to $30 \%$ of all cases of SCID. ${ }^{11}$ It includes defects in $R A G 1$ and $R A G 2$, Artemis (DCLRE1C), and the DNA protein kinase catalytic subunit $(D N A-P K c S) .{ }^{12,13}$ There are two principal types of patients with $\mathrm{T}-\mathrm{B}-\mathrm{NK}+\mathrm{SCID}$ associated with $\mathrm{V}(\mathrm{D}) \mathrm{J}$ recombination defects - those with and without radiation sensitivity.

\section{RAG I/RAG2}

Mutations in these genes are not associated with radiation sensitivity since these genes are expressed exclusively in lymphocytes and mediate the creation of double-strand DNA breaks at the sites of recombination and in signal sequences during $\mathrm{T}$ - and $\mathrm{B}$-cell receptor gene rearrangement. Nonhomologous end joining (NHEJ), which is a common machinery repair process found in many other tissues, is normal in individuals with $R A G 1$ or $R A G 2$ defects. Certain RAG mutations that result in partial protein expression and limited production of T and B cells are known to cause OS..$^{14,15}$ Hypomorphic RAG mutations have also been associated with a novel phenotype characterized by granuloma formation, EBV-related lymphoma, and survival into late childhood. ${ }^{15}$ 
According to our local experience, $\mathrm{XL}-\mathrm{SCID}$ is rare in Israel, while the most common phenotype is T-B- SCID due to $R A G 1 / R A G 2$ mutations. This phenomenon is probably due to the high rate of consanguinity among our Arab-origin population, which accounts for approximately $20 \%$ of the whole population, and for more than $50 \%$ of our SCID patients. ${ }^{16,17}$

Artemis and DNA-PKcs lead to increased sensitivity to ionizing radiation, since these gene products are important in the process of NHEJ required for repair of double-strand DNA breaks caused by radiation.

\section{Artemis}

Artemis deficiency is also known as Athabascan SCID (SCIDA), since a founder mutation in Artemis is found with increased frequency in Native Americans speaking one of the Athabascan family languages (eg, Apache, Navajo). ${ }^{18}$ In addition to T-cell maturation arrest, mutations in the Artemis gene result in B-cell differentiation arrest at the pre-B-cell-receptor checkpoint. ${ }^{19}$

\section{DNA-PKCs}

DNA-PKcs regulates Artemis by both phosphorylation and complex formation to permit enzymatic activities that are critical for V(D)J recombination and for NHEJ.

Intriguingly, the described functional missense $D N A$ $P K C s$ mutation does not affect either DNA-PKCs kinase activity or autophosphorylation - an important event that remodels the protein. Yet the clinical and cellular phenotype is similar to that caused by Artemis deficiency, suggesting that the mutation precludes Artemis activation, an event known to be DNA-PKcs dependent. ${ }^{20}$

\section{$\mathbf{T}-\mathbf{B}+\mathbf{N K}-\mathbf{S C I D}$}

Gene mutations affecting the integrity of the common gamma chain $(\gamma \mathrm{c}) / J A K 3$ signaling pathway result in the most common form of inherited T-B+NK- SCID. Despite the presence of normal numbers of $\mathrm{B}$ cells, cell activation, proliferation, and differentiation are impaired, resulting in profound hypogammaglobulinemia.

\section{X-linked SCID}

This form of SCID is due to defects in $\gamma$ c. Mutations in this gene lead to profound derangement of the immune system via the blockade of multiple cytokine pathways (IL-2R $\gamma \mathrm{c}$ is shared by the receptors of IL-4, IL-7, IL-9, IL-15, and IL-21), which are important for lymphocyte development and function..$^{21,22}$ In particular, IL-7 mediates expansion of early thymocyte progenitors, whereas IL-15 plays a role in NK cell development. Accordingly, patients with XL-SCID lack both $\mathrm{T}$ and NK cells, whereas they have a normal number of circulating B lymphocytes. ${ }^{23}$

XL-SCID patients usually have the classic clinical SCID phenotype. However, some patients have an atypical presentation such as an OS phenotype ${ }^{24}$ or a polymorphous lymphoproliferative disorder with Hodgkin-like features. ${ }^{25}$ The $\gamma \mathrm{c}$ subunit is also involved in growth hormone-receptor signaling. Thus, growth failure seen in children with XLSCID may also be due to the underlying genetic defect. ${ }^{26}$ The $\gamma$ chain mediates signal transduction via its physical association with a member of the Janus family of protein kinases, JAK3 $3{ }^{27}$ The primary therapy currently available for XL-SCID is hematopoietic cell transplantation. Of note is that, in some cases, gene therapy has been successful.

\section{JAK3 deficiency}

$J A K 3$ (encoded on chromosome 19p12-13.1) mediates cytokine signal transduction and is essential for lymphoid cell development. SCID due to JAK3 deficiency is rare, accounting only for approximately $6 \%$ of all cases of SCID. This AR form of T-B+NK- SCID is identical to XL-SCID in cellular and clinical phenotypes. Rarely, partial JAK3 defects associated with low amounts of functional protein can present with mild immunodeficiency. ${ }^{27}$

\section{$\mathbf{T}-\mathbf{B}+\mathbf{N K}+\mathbf{S C I D}$}

This SCID phenotype includes defects in the IL-7 receptor alpha chain (IL-7R $\alpha$; also called CD127), actin-regulating protein, coronin 1A (CORO1A), CD45 (also called proteintyrosine phosphatase receptor-type C; PTPRC), and the CD3 chains: $\mathrm{CD} 3$ delta (CD3D), CD3 epsilon (CD3E), and CD3 zeta $(\mathrm{CD} 3 \mathrm{Z})$.

\section{IL-7R $\alpha$ chain deficiency}

This defect is the third most common type of SCID. $I L-7 R \alpha$ (encoded on chromosome 5p13) plays a critical role in cytokine signaling that is necessary for T-cell development. Although both T-cell and B-cell progenitors express the functional IL-7 receptor that consists of $I L-7 R \alpha$ and a $\gamma c$ chain, this lymphocyte-receptor system is critical for the $\mathrm{T}$ lineage, but not for the $\mathrm{B}$ lineage, or for NK-cell development. IL-15 promotes NK-cell differentiation and maturation. Many patients have been identified with a classic SCID phenotype and they lack the $I L-7 R \alpha$ chain. ${ }^{28,29}$ Mutations in the $I L-7 R \alpha$ gene can also present with an OS phenotype. ${ }^{30}$ 


\section{Actin-regulating protein coronin IA deficiency}

Coronin 1A (encoded on chromosome 16p11.2) is involved in actin cytoskeleton regulation and is essential for T-cell immigration from the thymus to the secondary lymphoid organs. Defects in Coronin $1 A$ lead to an absence of normal peripheral $\mathrm{T}$ cells and to a classic SCID phenotype. The thymus is present, unlike in most other forms of SCID. ${ }^{31}$

\section{CD45 deficiency}

CD45, the leukocyte common antigen (encoded on chromosome 1q31-q32) is a transmembrane tyrosine phosphatase involved in TCR signaling and T-cell development in the thymus. Only a few patients have been identified with classic SCID due to CD45 deficiency. ${ }^{32}$

\section{CD3 complex component deficiencies}

The CD3 complex plays a major role in signaling through the TCR, which is essential for the normal maturation of $T$ cells. Mutations in the genes encoding CD3 chains (CD3 delta, CD3 epsilon, and CD3 zeta) appear to have an AR pattern of inheritance and have been reported in several patients. The clinical features are highly variable, depending upon the affected chain and mutation. Hypomorphic mutations in genes that are typically associated with SCID can allow residual T-cell development. In these cases, impaired cross-talk between thymocytes and thymic epithelial cells might compromise mechanisms of central tolerance, with failure to delete autoreactive $\mathrm{T}$ cells, and with impaired generation of regulatory T (Treg) cells. Accordingly, autoimmune manifestations are common, with infiltration of target tissues by activated and oligoclonal $\mathrm{T}$ lymphocytes. ${ }^{33-35}$

\section{Omenn syndrome}

OS is characterized by early postnatal diffuse exfoliative erythroderma, protracted diarrhea, lymphadenopathy, and hepatosplenomegaly, together with the typical recurrent severe infections. Laboratory investigations reveal prominent eosinophilia and lymphocytosis, mainly of $\mathrm{T}$ cells. These lymphocytes exhibit activation markers despite their highly restricted repertoire. Variable hypogammaglobulinemia with elevated levels of immunoglobulin E (IgE) and skewing toward TH2, the absence of B cells with minimal antibody response, and the absence of normal mitogenic responses are some of the common immune abnormalities in this syndrome. This peculiar phenotype was found to be associated with several different gene mutations including $R A G 1 / 2$ and
Artemis, $I L-7 R \alpha$, RNA-processing endoribonuclease, DNA ligase IV, ADA, and $\gamma c .{ }^{15,36}$

\section{$\mathbf{T}+\mathbf{B}+\mathbf{N K}+\mathbf{S C I D}$}

Other forms of combined immunodeficiency have many of the elements of the clinical presentation of SCID, including opportunistic infections. These forms of combined immunodeficiency are usually distinguished by distinctive laboratory features and other elements of the clinical presentation. However, in some cases, the distinction between SCID and combined immunodeficiency (CID) is only made by molecular testing.

In this chapter, we took the approach of dissecting the different types of SCID based on the normal process of development, activation, and maturation of $\mathrm{T}$ cells as described previously (Figure 1). Defects in T-cell development that occur beyond the CD4+ CD8+ doublepositive cell stage result in SCID with residual numbers of T lymphocytes. These SCID variants include: DNA ligase IV; Cernunnos-XLF; CD3 $\gamma$ deficiency; MHC class I deficiency; CD8 deficiency; MHC class II deficiency; IL-2 receptor alpha chain (CD25) deficiency; p561ck deficiency; ZAP70 deficiency; ORAI1/CRACM1 and STIM1 deficiencies; signal transducer and activator of transcription $5 \mathrm{~b}$ (STAT5b) deficiency; winged-helix nude (FOXN1) deficiency; PNP; CD40 and CD40 ligand deficiencies; Itk; and dedicator of cytokinesis 8 (DOCK8) deficiency.

\section{DNA ligase IV (LIG4)}

The DNA ends must be ligated as part of the DNA repair process and this is implemented by an LIG4-XRCC4 complex. XRCC4 (X-ray-complementing Chinese hamster gene 4) has no known enzymatic activity, but functions as a scaffolding protein that helps attract other repair proteins to the DNA break. XRCC4 stabilizes LIG4 and enhances its activity.

Patients with LIG4 syndrome present with microcephaly, developmental delay, facial dysmorphism, increased susceptibility to tumors, and a variable degree of immunodeficiency that ranges from SCID/OS, to hypogammaglobulinemia with impaired class-switch recombination, to moderate, or even very modest defects in $\mathrm{T}$ - and B-cell immunity. ${ }^{37-39}$

\section{Cernunnos-XLF}

Defects in the NHEJ factor 1 gene (NHEJI gene) that codes for the protein Cernunnos, also known as the XRCC4-like factor (XLF), lead to a $\mathrm{T}-\mathrm{B}-\mathrm{NK}+$ radiation-sensitive SCID phenotype with associated developmental delay and microcephaly. $\mathrm{T}$ cells are absent, except for memory 


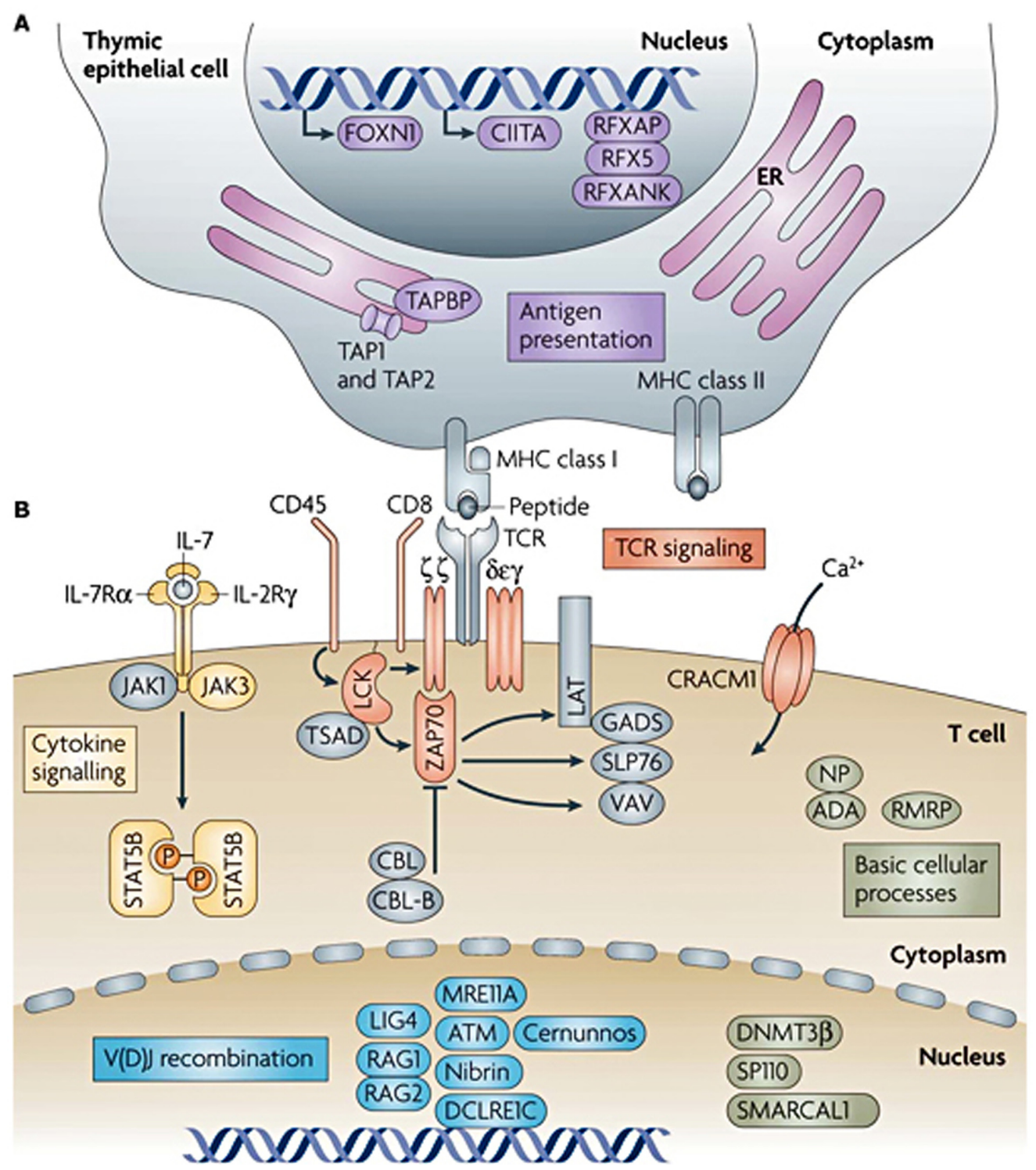

Figure I Genes with mutations that cause monogenic, severe T-cell immunodeficiency in humans can be intrinsic to the thymic epithelium or to T cells. (A) Genetic defects that are intrinsic to thymic epithelial cells ultimately affect the antigen-presentation pathway. (B) Genetic defects that are intrinsic to $T$ cells include those that affect $T$-cell receptor (TCR) signaling, cytokine signaling, somatic recombination, or basic cellular processes. Other genes that are important to these pathways or processes, but have not been linked to severe T-cell deficiency in humans are shown in grey. Copyright @ 2008 . Nature Publishing Group. Adapted with permission from Liston A, Enders A, Siggs OM. Unravelling the association of partial T-cell immunodeficiency and immune dysregulation. Nat Rev Immunol. 2008;8:546.8

Abbreviations: ADA, adenosine deaminase; ATM, ataxia-telangiectasia mutated; CBL, Casitas B-lineage lymphoma; CIITA, class II transactivator; DCLREIC, DNA crosslink

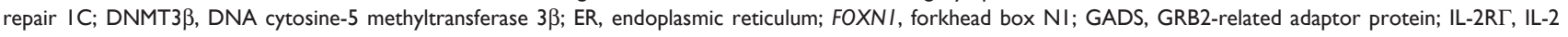
receptor $\Gamma$-chain; IL-7, interleukin-7; IL-7R $\alpha$, IL-7 receptor $\alpha$-chain; JAK, Janus kinase; LAT, linker for activation of T cells; LIG4, ligase IV; MRE I IA, meiotic recombination I I homolog A; Nibrin, Nijmegen breakage syndrome I; NP, nucleoside phosphorylase; CRACMI, calcium release-activated calcium modulator I; RAG, recombination-activating gene; RFX5, regulatory factor X5; RFXANK, RFX-associated ankyrin-containing protein; RFXAP, RFX-associated protein; RMRP, RNA component of mitochondrial RNAprocessing endoribonuclease; SLP76, SRC-homology-2-domain-containing leukocyte protein of $76 \mathrm{kDa}$; SMARCALI, SWI/SNF-related matrix-associated actin-dependent regulator of chromatin a-like I; SPII0, SPIIO nuclear body protein; STAT5B, signal transducer and activator of transcription 5B; TAP, transporter associated with antigen processing; TAPBP, TAP-binding protein; TSAD, T-cell-specific adaptor protein; ZAP70, $\zeta$-chain-associated protein kinase of $70 \mathrm{kDa}$.

$\mathrm{T}$ cells, and patients have a progressive loss of $\mathrm{B}$ cells. XLF-Cernunnos is a core protein of the NHEJ pathway of DNA double-strand break repair. The roles of the Cernunnos-XLF protein are still being elucidated. Crystallography suggests that it is part of the XRCC4-LIG4 complex. It enhances the DNA ligation activity of the XRCC4-LIG4 complex by promoting its re-adenylation and appears to play an essential role in gap filling by either polymerase during NHEJ, suggesting that it plays a major role in aligning the two DNA ends in the repair complex. ${ }^{40,41}$

\section{CD3 $\gamma$ deficiency}

CD3 $\gamma$ deficiency is an AR immunodeficiency caused by mutations in the gene coding for T-cell surface glycoprotein 
CD3 $\gamma$ chain precursors. Affected patients have decreased T-cell numbers and function. B cells are variably affected. Patients with CD3 $\gamma$ deficiency have varying phenotypes, with some having SCID-like symptoms and some having a benign course. ${ }^{42}$

\section{MHC class I deficiency (Bare lymphocyte syndrome type I)}

Most patients with MHC I expression abnormalities exhibit decreased or absent MHC I expression on the cell surface, low numbers of CD8+ T cells, and decreased NK cell-killing activity. However, they have normal antibody-dependent cell-mediated cytotoxicity. ${ }^{43}$ The clinical presentation is highly variable, depending upon the amount of $\mathrm{MHC}$ class I expression. Affected patients with a severe reduction in MHC class I expression also tend to have necrotizing granulomatous skin lesions. ${ }^{44}$ Some patients with $\mathrm{MHC}$ class I deficiency have defects in the transporter associated with antigen processing: (TAP) 1, TAP2, or tapasin. TAP1 and TAP2 are required for peptide transport from the cytosol into the ER lumen, where the assembly of the MHC class I complex takes place. Tapasin serves as a docking site that is specific for interaction with class I MHC molecules, which is essential for peptide loading and expression. The exact defect has not been identified in other patients with $\mathrm{MHC}$ class I deficiency. The inheritance pattern is unclear due to its rarity. ${ }^{45}$

\section{CD8 deficiency}

CD8 is a TCR accessory molecule that binds to class I MHC. CD8 is primarily expressed on cytotoxic T cells, but is also found on NK cells. A single patient has been described with symptomatic CD8 deficiency due to a homozygous mutation in the gene encoding the CD8 alpha chain (CD8 $\alpha)$ on chromosome $2 \mathrm{p} 12$. He had recurrent sinopulmonary infections, which suggested a humoral deficiency. However, his immunoglobulin levels and specific antibody titers were normal. CD4+ T-cell, B-cell, and NK-cell percentages and absolute counts were normal, but CD8+ T cells were completely absent. Two younger sisters, who also had absent CD8+ T cells, were asymptomatic at the time of the report, reflecting the importance of other factors (such as epigenetics and infections) in these complex diseases. ${ }^{46}$

\section{MHC class II deficiency (Bare lymphocyte syndrome type II)}

This is an AR disease. Both constitutive and induced MHC class II expressions are compromised. The exact molecular defects have not been identified in most patients, but are suspected to involve mutations in MHCII promoter complex DNA-binding regulatory factors (CIITA-class II transactivator, RFX5, RFXAP, and RFXANK). The majority of identified defects are RFXANK mutations (chromosome 19p12). The disease is more common in certain geographic regions (North Africa ${ }^{47}$ and Palestinians [Broides A, email communication, 2011]). Patients with MHC II expression abnormalities exhibit complete absence of MHC II expression on B cells, a normal number of B cells in peripheral blood, hypogammaglobulinemia, and poor specific-antibody responses. In addition, CD4 lymphopenia, with a proportional increase in $\mathrm{CD} 8$, a normal number of $\mathrm{T}$ cells in peripheral blood, but with decreased in vitro T-cell response to antigens are observed. Class II MHC deficiency generally results in a clinical picture of severe combined immune deficiency. However, milder cases have been described. ${ }^{48}$

\section{Interleukin-2 receptor alpha chain (CD25) deficiency}

CD25 deficiency is extremely rare. Only a few patients have been described with lesions in the IL2-R $\alpha$ gene encoding the $\alpha$-chain of the IL-2 receptor. This immunodeficiency is characterized by normal to modestly decreased numbers of circulating $\mathrm{T}$ cells, displaying abnormal proliferation, but normal B-cell development. Extensive lymphocytic infiltration of tissues including the lung, liver, gut, and bone, is observed, accompanied by tissue atrophy, and inflammation. ${ }^{49}$ A phenotype resembling the syndromes of immune dysregulation, polyendocrinopathy, enteropathy, and X-linked (IPEX) - a syndrome that is more often associated with mutations of the transcription factor FOXP3 - has also been described..$^{50}$

\section{Lymphocyte-specific protein tyrosine kinase (Lck or p56lck) deficiency}

Initial transduction of antigen-binding signals from the TCR/CD3 complex is primarily dependent upon two protein tyrosine kinases: Lck and ZAP-70. Several patients have been reported with a deficiency of Lck, which was activated upon engagement of the TCR-CD3 complex. Lck is a $56-\mathrm{kDa}$ member of the Src-family tyrosine kinase family. Deficiency of Lck is reported to result in an immunodeficiency characterized by selective CD4 lymphopenia, decreased CD28 expression on CD8 cells, and low, to absent immunoglobulins. Patients demonstrate the typical failure to thrive that is seen in SCID. ${ }^{51}$ 


\section{ZAP-70 deficiency}

ZAP-70 deficiency is a rare combined immunodeficiency with an AR pattern of inheritance. Zeta chain-associated $70-\mathrm{kDa}$ protein kinase (ZAP-70) is a signaling molecule associated with the TCR complex, which is expressed primarily in T cells. Most mutations occur within the kinase domain of the ZAP-70 protein, and significantly affect both protein stability, and catalytic activity. Deficiency of ZAP-70 (which was originally described in a Mennonite family) is characterized by the selective absence of circulating CD8+ $T$ cells and by abundant $C D 4+T$ cells in the peripheral blood that are unresponsive to TCR-mediated stimuli in vitro. ${ }^{52} \mathrm{All}$ patients with ZAP-70 deficiency have normal to elevated numbers of circulating lymphocytes. ${ }^{53}$

\section{ORAII/CRACMI and STIMI deficiencies}

Lymphocyte activation after antigen stimulation is dependent upon store-operated entry of $\mathrm{Ca}^{2+}$ across the plasma membrane via $\mathrm{Ca}^{2+}$ release-activated $\mathrm{Ca}^{2+}$ (CRAC) channels. OraI1 or calcium release-activated calcium modulator 1 (CRACM1) is the pore-forming subunit of the CRAC channel. Stromal interaction molecule 1 (STIM1) senses release of $\mathrm{Ca}^{2+}$ from endoplasmic reticulum stores and activates CRAC channels in the plasma membrane. Sustained $\mathrm{Ca}^{2+}$ influx induces expression of IL-2 and other cytokines. The clinical phenotypes of the ORAI1 defect and of the STIM defect are similar. Mutations in ORAI1 on chromosome 12q24 and STIM1 on chromosome 11q15.5 appear to have AR inheritance. The laboratory findings are similar for both of these defects. Lymphocyte counts are normal to slightly reduced, and immunoglobulin levels are normal to elevated. However, the T-cell proliferative response to mitogens and antigens is compromised and specific antibody response to vaccination is impaired. Non-progressive muscular hypotonia and abnormalities in dental enamel are seen in both ORAI1 and STIM1 deficiencies. Extensive ectodermal defects (ectodermal dysplasia and anhydrosis) are more prominent in patients with ORAI1 deficiency. Unique features of STIM1 deficiency are severe autoimmunity and partial iris hypoplasia. ${ }^{54,55}$

\section{Signal transducer and activator of transcription 5b (STAT5b) deficiency}

Several patients have been identified with mutations in the STAT5b gene that cause a defect in the signaling pathways of receptors for IL-2, IL-4, macrophage colony-stimulating factor, and growth hormone. CD4+CD25+ regulatory T cells are decreased in number in patients with $S T A T 5 b$ deficiency. Other immunologic parameters are variable, including T-, B-, and NK-cell levels, and T-cell proliferation. Patients present with signs of growth-hormone insensitivity, including short stature, a prominent forehead and saddle nose, and a highpitched voice. Associated manifestations include eczema and autoimmunity as well. ${ }^{56}$

\section{Winged-helix nude (FOXNI) deficiency}

This extremely rare disorder is caused by a homozygous defect in the forkhead box N1 (FOXN1) gene, which is the gene mutated in "nude" SCID mice. FOXN1 is a member of the winged-helix domain family of transcription factors. This protein is involved in the development of the thymus as well as formation of hair and nails. It also may be involved in brain and neural tube development. Patients with defects in this gene have decreased circulating $\mathrm{T}$ cells, mainly due to low levels of CD4+ T cells. T-cell proliferative responses to mitogens were abnormal. Congenital alopecia and nail dystrophy are characteristic features. Additional defects, including spina bifida and anencephaly, have been described in a fetus..$^{57,58}$

\section{Purine nucleoside phosphorylase (PNP) deficiency}

PNP follows ADA in the purine salvage pathway, and PNP deficiency causes SCID because excess deoxyguanosine and deoxyguanosine triphosphate lead to increased apoptosis of lymphocytes, mainly immature T lymphocytes. ${ }^{59}$ PNP-deficient cells do not produce uric acid and, therefore, low uric acid in serum $(<2 \mathrm{mg} / \mathrm{dL})$ supports the diagnosis PEG-PNP is not commercialized and gene therapy is still experimental in mice. HSCT is the only available therapy, but it does not correct the severe neurological manifestations usually present (hypertonia, hypotonia, ataxia, psychomotor delay). Autoimmunity (hemolytic anemia, autoimmune thrombocytopenia, neutropenia, arthritis, etc) and neoplasia are also frequent. ${ }^{59,60}$

\section{CD40 and CD40 ligand deficiencies}

CD40 is a molecule on the surface of B cells and mononuclear cells (including dendritic cells) that interacts with its CD40 ligand $(\mathrm{CD} 40 \mathrm{~L})$ on the surface of activated CD4+ T cells. Defects in CD40L or CD40 cause defective isotype switching and impaired dendritic cell signaling. Mutations in CD40L 
(CD154) are responsible for most cases of hyper-IgM (HIGM) syndrome.$^{61}$ The principal laboratory findings of HIGM syndrome are low serum levels of $\operatorname{IgG}$ and $\operatorname{IgA}$, in combination with normal or elevated concentrations of IgM. Circulating $\mathrm{B}$ cells are normal in number, but exclusively express cellsurface IgM and IgD. Vaccination may elicit specific IgM responses. No other isotypes are produced and there is no B-cell memory. CD40L is located on the $\mathrm{X}$ chromosome, while the gene encoding CD40 (TNF-receptor superfamily member 5 or TNFRSF5) is located on chromosome 20q12q13.2. Mutations in this gene underlie a clinically indistinguishable disorder with AR inheritance. ${ }^{62}$ Patients with HIGM usually present within the first two years of life with the combination of recurrent respiratory tract infections with encapsulated bacteria and opportunistic infections. Lymphadenopathy and hepatosplenomegaly are often present. They are also prone to neutropenia, thrombocytopenia, anemia, sclerosing cholangitis, cirrhosis, and lymphoproliferative disease. Increased rates of malignancy such as hepatocellular, bile duct, and neuroendocrine carcinomas are also reported. ${ }^{63}$

\section{Interleukin-2 tyrosine kinase (Itk) deficiency}

Itk deficiency is characterized by lymphoproliferation and severe immune dysregulation following EBV infection and is inherited as an AR disorder. Itk is a member of the TEC kinase family. These proteins are important mediators of antigen-receptor signaling in lymphocytes, and Itk is believed to be the predominant TEC kinase in T cells, and one of the key molecules involved in NKT cell maturation and survival ${ }^{64}$ Itk deficiency was recently identified in female siblings who presented with EBV-associated lymphoproliferation, an absence of NKT cells, and hemophagocytic lymphohistiocytosis. ${ }^{65}$

\section{Dedicator of cytokinesis 8 (DOCK8) deficiency}

Several patients have been identified with loss of functional homozygous or compound heterozygous mutations in an uncharacterized gene, DOCK8, which is expressed in lymphocytes. Most patients have low absolute lymphocyte counts, including low T cells; B and NK cells are also low in many patients. Most patients also have eosinophilia and elevated IgE. IgM levels are low, but many patients have increased IgG levels. IgG antibody responses to bacterial and viral antigens are variable. ${ }^{66}$ Common clinical features include recurrent respiratory tract infections, extensive cutaneous viral and bacterial (Staphylococcus aureus) infections, severe atopy, and susceptibility to cancer (vulvar, facial, and anal squamous-cell dysplasia and carcinomas, and T-cell lymphoma/leukemia). ${ }^{66}$

\section{Other well-defined immunodeficiency syndromes}

In addition to the above-described syndromes, there are other well-defined primary immunodeficiency disease (PID) syndromes with a variable degree of immune dysfunction such as Wiskott-Aldrich syndrome, DNA repair defects (ataxia telangiectasia, Bloom and Nijmegen syndromes), and others. Some of them can present with the typical clinical and laboratory features of SCID/CID. Herein, we discuss some of these syndromes in detail.

\section{DiGeorge syndrome (DGS)}

DGS (OMIM 188400) results from dysmorphogenesis of the third and fourth pharyngeal pouches during early embryogenesis, leading to hypoplasia or aplasia of the thymus and parathyroid glands. Other structures forming at the same age are also frequently affected, resulting in anomalies of maxilla, mandible, aortic arch, cardiac outflow tract, and external/ middle ear. The classical presentation of DGS is the triad of conotruncal cardiac anomalies, hypoplastic thymus, and hypocalcemia, although the phenotype is variable. Palatal abnormalities and developmental delay are common.

Approximately $90 \%$ of patients with DGS have spontaneously arising heterozygous microdeletions in chromosome 22q11.2. Defects in the gene encoding the T-box transcription family member, TBX1, are responsible for the DGS phenotype. The basis for the syndrome without the characteristic deletion is often unknown. Some patients will have a known exposure to toxins such as isotretinoin or maternal alcohol ingestion. There is also a small subset that shows the deletion of chromosome 10p13-14.

The immunodeficiency has been characterized as either complete or partial, based on the level of immunologic function. The minority of patients (approximately 1\%) have a complete absence of thymic tissue and profound immunodeficiency. Patients with complete DGS resemble patients with SCID. Atypical cases phenotypically appear to be similar to OS. Complete DGS is fatal if not recognized and treated with a thymic or HSC transplant. ${ }^{67}$

\section{Cartilage-hair hypoplasia (CHH)}

CHH (OMIM 250250) is an AR, predominantly T-cell deficiency associated with metaphyseal chondrodysplasia, a form 
of short-limb dwarfism. Associated features may include fine sparse hair, cellular and humoral immunodeficiencies, Hirschsprung disease, hematologic and skin malignancies, autoimmune disease, and bronchiectasis. The responsible gene for $\mathrm{CHH}$ has been mapped to 9p21-p12 and shown to be the gene encoding the ribonuclease mitochondrial RNAprocessing (RMRP) protein.

Phenotypic heterogeneity is great and the immunodeficiency is variable. Cell-mediated immunodeficiency is most commonly reported. SCID is known to occur in the setting of CHH. SCID may present with severe T- and B-cell functional defects, but with quantifiable cell counts, or with an OS phenotype. Stem-cell transplantation has resulted in immunologic reconstitution in some $\mathrm{CHH}$ patients with the SCID phenotype. ${ }^{68}$

\section{Hereditary folate malabsorption (HFM)}

HFM (OMIM 229050) is an extremely rare AR cause of folic acid deficiency. It presents early in life with diarrhea, failure to thrive, and megaloblastic anemia often accompanied by leukopenia, and/or thrombocytopenia. HFM patients can develop progressive neurologic deterioration (ataxia, seizures, and mental retardation) unless they are treated promptly and aggressively. Family studies have shown this disorder to be due to mutations in a proton-coupled folate transporter (PCFT), resulting in abnormal folate transport across the gastrointestinal tract and the blood-brain barrier. HFM can present with life-threatening infections due to profound immunological defects that may mimic SCID. The immune defects are fully reversible with adequate folate repletion. ${ }^{69}$

\section{Hoyeraal-Hreidarsson (HH)}

HH syndrome (OMIM 300240) represents a severe variant of dyskeratosis congenita (DC). This rare, progressive, multisystemic disorder is characterized by intrauterine growth retardation, microcephaly, cerebellar hypoplasia, mental retardation, early onset bone marrow failure, progressive combined immune deficiency, and aplastic anemia. DC and $\mathrm{HH}$ result from heterogeneous telomere defects. ${ }^{70}$

\section{Gene therapy}

Gene therapy for SCID is still in its infancy. Virus-based vectors are widely used in HSC gene therapy, and have the ability to integrate permanently into genomic DNA, thus driving long-term expression of corrective genes in all hematopoietic lineages. To date, HSC gene therapy has been successfully employed in the clinic for improving clinical outcomes in small numbers of patients with ADA SCID and XL-SCID.

ADA deficiency was the first genetic disorder to be treated by gene therapy; however, the first cases failed to achieve sustained T-cell and normal ADA levels. ${ }^{71}$ Since 2000, over 30 patients with ADA deficiency have been treated with gene therapy throughout the world. Most cases have shown successful outcomes, achieving immune reconstitution, restoration of thymic activity, systemic detoxification, and long-term engraftment. ${ }^{72}$

The possible role of gene therapy continues to evolve and a second trial was carried out on XL-SCID patients. To date, gene therapy results are available for 20 patients with a typical XL-SCID. Most patients have shown substantial improvements in clinical and immunological features. However, five of the 20 patients developed a T-cell acute leukemia 2 to 5.5 years after gene therapy. In all cases, it was found that the abnormal clone had one or two provirus integrations within a proto-oncogene locus. Many other genomic abnormalities were found. Accordingly, the clinical trials were discontinued. Today, gene therapy is allowed to continue on a case-by-case basis if no other treatment is available. $^{73,74}$

Numerous studies have been performed to understand the molecular basis of vector-mediated genotoxicity, with the aim of developing safer vectors and lower risk gene-therapy protocols. One such approach involves self-inactivating gammaretrovirus and lentivirus-based vectors, which, when integrated, lack enhancer and promoter sequences from the long terminal repeat. ${ }^{75}$ These new vectors should decrease or alleviate the risks of proto-oncogene activation by insertional mutagenesis. ${ }^{76}$

Meanwhile, vector-mediated genotoxicity has fostered a growing interest for alternative strategies, referred to as "targeted approaches," that consist of replacing random integration of therapeutic transgenes by targeted insertion or even correction of the deleterious mutation. Results are beginning to accumulate for clinical trials using new viral vectors ${ }^{77}$ and the first clinical trial using a targeted approach has been initiated. ${ }^{78}$ Although additional time is needed to evaluate, more precisely, the potentials and limits of each method, targeted approaches remain today, at least conceptually, more attractive than classical gene-transfer techniques. ${ }^{79}$

\section{Disclosure}

The authors report no conflicts of interest in this work. 


\section{References}

1. Bonilla FA. Severe combined immunodeficiency (SCID): An overview. In: Stiehm ER, editor. UpToDate. Waltham, MA: UpToDate; 2012.

2. International Union of Immunological Societies Expert Committee on Primary Immunodeficiencies; Notarangelo LD, Fischer A, Geha RS, et al. Primary immunodeficiencies: 2009 update. J Allergy Clin Immunol. 2009;124(6):1161-1178.

3. Lee PP, Chan KW, Chen TX, et al. Molecular diagnosis of severe combined immunodeficiency: Identification of IL2RG, JAK3, IL7R, DCLRE1C, RAG1, and RAG2 mutations in a cohort of Chinese and southeast Asian children. J Clin Immunol. 2011;31(2):281-296.

4. Suliaman F, Al-Ghonaium A, Harfi H. High incidence of severe combined immune deficiency in the Eastern Province of Saudi Arabia. Pediatr Asthma Allergy Immunol. 2006;19(1):14-18.

5. Golan H, Dalal I, Garty BZ, et al. The incidence of primary immunodeficiency syndromes in Israel. Isr Med Assoc J. 2002;4(11):868-871.

6. Fischer A, Notarangelo LD. Combined immunodeficiencies. In: Stiehm ER, Ochs HD, Winkelstein JA, editors. Immunologic Disorders in Infants and Children, 5th ed. Philadelphia, PA: Elsevier Saunders; 2004:3-16.

7. Buckley RH. T lymphocytes, B lymphocytes, and natural killer cells. In: Behrman RE, Kliegman RM, Jenson HB, editors. Nelson Textbook of Pediatrics, 19th ed. Philadelphia, PA: W.B. Saunders; 2011:722.

8. Hershfield MS. Genotype is an important determinant of phenotype in adenosine deaminase deficiency. Curr Opin Immunol. 2003;15(5): $571-577$.

9. Gaspar HB. Bone marrow transplantation and alternatives for adenosine deaminase deficiency. Immunol Allergy Clin North Am. 2010;30(2):221-236.

10. Lagresle-Peyrou C, Six EM, Picard C, et al. Human adenylate kinase 2 deficiency causes a profound hematopoietic defect associated with sensorineural deafness. Nat Genet. 2009;41(1):106-111.

11. de Villartay JP. V(D)J recombination deficiencies. Adv Exp Med Biol. 2009;650:46-58.

12. Schwarz K, Hansen-Hagge TE, Knobloch C, Friedrich W, Kleihauer E, Bartram CR. Severe combined immunodeficiency (SCID) in man: B cell-negative (B-) SCID patients exhibit an irregular recombination pattern at the JH locus. J Exp Med. 1991;174(5):1039-1048.

13. Nicolas N, Moshous D, Cavazzana-Calvo M, et al. A human severe combined immunodeficiency (SCID) condition with increased sensitivity to ionizing radiations and impaired V(D)J rearrangements defines a new DNA recombination/repair deficiency. $J$ Exp Med. 1998;188(4):627-634.

14. Villa A, Sobacchi C, Notarangelo LD, et al. V(D)J recombination defects in lymphocytes due to RAG mutations: Severe immunodeficiency with a spectrum of clinical presentations. Blood. 2001;97(1):81-88.

15. Niehues T, Perez-Becker R, Schuetz C. More than just SCID-the phenotypic range of combined immunodeficiencies associated with mutations in the recombinase activating genes (RAG) 1 and 2. Clin Immunol. 2010;135(2):183-192.

16. Tabori U, Mark Z, Amariglio N, et al. Detection of RAG mutations and prenatal diagnosis in families presenting with either $\mathrm{T}-\mathrm{B}-$ severe combined immunodeficiency or Omenn's syndrome. Clin Genet. 2004;65(4):322-326.

17. Dalal I, Tasher D, Somech R, et al. Novel mutations in RAG1/2 and ADA genes in Israeli patients presenting with T-B- SCID or Omenn syndrome. Clin Immunol. 2011;140(3):284-290.

18. Li L, Moshous D, Zhou Y, et al. Founder mutation in Artemis, an SNM1like protein, causes SCID in Athabascan-speaking Native Americans. J Immunol. 2002;168(12):6323-6329.

19. Noordzij JG, Verkaik NS, van der Burg M, et al. Radiosensitive SCID patients with Artemis gene mutations show a complete B-cell differentiation arrest at the pre-B-cell receptor checkpoint in bone marrow. Blood. 2003;101(4):1446-1452.

20. van der Burg M, Ijspeert H, Verkaik NS, et al. A DNA-PKes mutation in a radiosensitive $\mathrm{T}-\mathrm{B}-\mathrm{SCID}$ patient inhibits Artemis activation and nonhomologous end-joining. J Clin Invest. 2009;119(1):91-98.
21. Noguchi M, Yi H, Rosenblatt HM, et al. Interleukin-2 receptor gamma chain mutation results in X-linked severe combined immunodeficiency in humans. Cell. 1993;73(1):147-157.

22. Kovanen PE, Leonard WJ. Cytokines and immunodeficiency diseases: Critical roles of the gamma(c)-dependent cytokines interleukins 2, 4, $7,9,15$, and 21, and their signaling pathways. Immunol Rev. 2004;202: 67-83.

23. Rochman Y, Spolski R, Leonard WJ. New insights into the regulation of T cells by gamma(c) family cytokines. Nat Rev Immunol. 2009;9(7): 480-490.

24. Wada T, Yasui M, Toma T, et al. Detection of T lymphocytes with a second-site mutation in skin lesions of atypical X-linked severe combined immunodeficiency mimicking Omenn syndrome. Blood. 2008;112(5):1872-1875.

25. Slatter MA, Angus B, Windebank K, et al. Polymorphous lymphoproliferative disorder with Hodgkin-like features in common $\gamma$-chain-deficient severe combined immunodeficiency. J Allergy Clin Immunol. 2011;127(2):533-535.

26. De Ravin SS, Shum E, Zarember KA, et al. Short stature in partially corrected X-linked severe combined immunodeficiency-suboptimal response to growth hormone. J Pediatr Endocrinol Metab. 2008;21(11): 1057-1063.

27. O'Shea JJ, Notarangelo LD, Johnston JA, Candotti F. Advances in the understanding of cytokine signal transduction: The role of Jaks and STATs in immunoregulation and the pathogenesis of immunodeficiency. J Clin Immunol. 1997;17(6):431-447.

28. Puel A, Ziegler SF, Buckley RH, Leonard WJ. Defective IL7R expression in $\mathrm{T}(-) \mathrm{B}(+) \mathrm{NK}(+)$ severe combined immunodeficiency. Nat Genet. 1998;20(4):394-397.

29. Roifman CM, Zhang J, Chitayat D, Sharfe N. A partial deficiency of interleukin-7R alpha is sufficient to abrogate T-cell development and cause severe combined immunodeficiency. Blood. 2000;96(8): 2803-2807.

30. Villa A, Notarangelo LD, Roifman CM. Omenn syndrome: Inflammation in leaky severe combined immunodeficiency. J Allergy Clin Immunol. 2008;122(6):1082-1086.

31. Shiow LR, Roadcap DW, Paris K, et al. The actin regulator coronin $1 \mathrm{~A}$ is mutant in a thymic egress-deficient mouse strain and in a patient with severe combined immunodeficiency. Nat Immunol. 2008;9(11): 1307-1315.

32. Kung C, Pingel JT, Heikinheimo M, et al. Mutations in the tyrosine phosphatase CD45 gene in a child with severe combined immunodeficiency disease. Nat Med. 2000;6(3):343-345.

33. Recio MJ, Moreno-Pelayo MA, Kiliç SS, et al. Differential biological role of CD3 chains revealed by human immunodeficiencies. J Immunol. 2007;178(4):2556-2564.

34. Roberts JL, Lauritsen JP, Cooney M, et al. T-B+NK+ severe combined immunodeficiency caused by complete deficiency of the CD3 $\zeta$ subunit of the T-cell antigen receptor complex. Blood. 2007;109(8): 3198-3206.

35. Dadi HK, Simon AJ, Roifman CM. Effect of CD3 delta deficiency on maturation of alpha/beta and gamma/delta T-cell lineages in severe combined immunodeficiency. N Engl J Med. 2003;349(19):1821-1828.

36. Poliani PL, Facchetti F, Ravanini M, et al. Early defects in human T-cell development severely affect distribution and maturation of thymic stromal cells: Possible implications for the pathophysiology of Omenn syndrome. Blood. 2009;114(1):105-108.

37. van der Burg M, van Veelen LR, Verkaik NS, et al. A new type of radiosensitive $\mathrm{T}-\mathrm{B}-\mathrm{NK}+$ severe combined immunodeficiency caused by a LIG4 mutation. J Clin Invest. 2006;116(1):137-145.

38. Buck D, Moshous D, de Chasseval R, et al. Severe combined immunodeficiency and microcephaly in siblings with hypomorphic mutations in DNA ligase IV. Eur J Immunol. 2006;36(1):224-235.

39. Omenn syndrome is associated with mutations in DNA ligase IV. Grunebaum E, Bates A, Roifman CM. J Allergy Clin Immunol. 2008;122(6):1219-1220. 
40. Buck D, Malivert L, de Chasseval R, et al. Cernunnos, a novel nonhomologous end-joining factor, is mutated in human immunodeficiency with microcephaly. Cell. 2006;124(2):287-299.

41. Ahnesorg P, Smith P, Jackson SP. XLF interacts with the XRCC4-DNA ligase IV complex to promote DNA nonhomologous end-joining. Cell. 2006;124(2):301-313.

42. Arnaiz-Villena A, Timon M, Rodriguez-Gallego C, et al. T lymphocyte signalling defects and immunodeficiency due to the lack of CD3 gamma. Immunodeficiency. 1993;4(1-4):121-129.

43. Schuurman RK, van Rood JJ, Vossen JM, et al. Failure of lymphocytemembrane HLA-A and -B expression in two siblings with combined immunodeficiency. Clin Immunol Immunopathol. 1979;14(4): 418-434.

44. Moins-Teisserenc HT, Gadola SD, Cella M, et al. Association of a syndrome resembling Wegener's granulomatosis with low surface expression of HLA class-I molecules. Lancet. 1999;354(9190): 1598-1603.

45. Furukawa H, Murata S, Yabe T, et al. Splice acceptor site mutation of the transporter associated with antigen processing-1 gene in human bare lymphocyte syndrome. J Clin Invest. 1999;103(5):755-758.

46. de la Calle-Martin O, Hernandez M, Ordi J, et al. Familial CD8 deficiency due to a mutation in the CD8 alpha gene. J Clin Invest 2001;108(1):117-123.

47. Masternak K, Barras E, Zufferey M, et al. A gene encoding a novel RFX-associated transactivator is mutated in the majority of $\mathrm{MHC}$ class II deficiency patients. Nat Genet. 1998;20(3):273-277.

48. Wiszniewski W, Fondaneche MC, Le Deist F, et al. Mutation in the class II trans-activator leading to a mild immunodeficiency. J Immunol. 2001;167(3):1787-1794.

49. Sharfe N, Dadi HK, Shahar M, Roifman CM. Human immune disorder arising from mutation of the alpha chain of the interleukin-2 receptor. Proc Natl Acad Sci USA. 1997;94(7):3168-3171.

50. Torgerson TR, Ochs HD. Immune dysregulation, polyendocrinopathy, enteropathy, X-linked syndrome: A model of immune dysregulation. Curr Opin Allergy Clin Immunol. 2002;2(6):481-487.

51. Goldman FD, Ballas ZK, Schutte BC, et al. Defective expression of p56lck in an infant with severe combined immunodeficiency. J Clin Invest. 1998;102(2):421-429.

52. Roifman CM, Hummel D, Martinez-Valdez H, et al. Depletion of CD8+ cells in human thymic medulla results in selective immune deficiency. J Exp Med. 1989;170(6):2177-2182.

53. Arpaia E, Shahar M, Dadi H, Cohen A, Roifman CM. Defective T cell receptor signaling and CD8+ thymic selection in humans lacking zap-70 kinase. Cell. 1994;76(5):947-958.

54. Feske S, Gwack Y, Prakriya M, et al. A mutation in Orall causes immune deficiency by abrogating CRAC channel function. Nature. 2006;441(7090):179-185.

55. Picard C, McCarl CA, Papolos A, et al. STIM1 mutation associated with a syndrome of immunodeficiency and autoimmunity. $N$ Engl J Med 2009;360(19):1971-1980.

56. Kofoed EM, Hwa V, Little B, et al. Growth hormone insensitivity associated with a STAT5b mutation. $N$ Engl J Med. 2003;349(12): 1139-1147.

57. Frank J, Pignata C, Panteleyev AA, et al. Exposing the human nude phenotype. Nature. 1999;398(6727):473-474.

58. Amorosi S, D’Armiento M, Calcagno G, et al. FOXN1 homozygous mutation associated with anencephaly and severe neural tube defect in human athymic Nude/SCID fetus. Clin Genet. 2008;73(4):380-384.

59. Markert ML. Purine nucleoside phosphorylase deficiency. Immunodefic Rev. 1991;3(1):45-81.

60. Dalal I, Grunebaum E, Cohen A, Roifman CM. Two novel mutations in a purine nucleoside phosphorylase (PNP)-deficient patient. Clin Genet. 2001;59(6):430-437.

61. Allen RC, Armitage RJ, Conley ME, et al. CD40 ligand gene defects responsible for X-linked hyper-IgM syndrome. Science. 1993;259(5097):990-993.
62. Lanzi G, Ferrari S, Vihinen M, et al. Different molecular behavior of CD40 mutants causing hyper-IgM syndrome. Blood. 2010;116(26): 5867-5874.

63. Ferrari S, Giliani S, Insalaco A, et al. Mutations of CD40 gene cause an autosomal recessive form of immunodeficiency with hyper IgM. Proc Natl Acad Sci U S A. 2001;98(22):12614-12619.

64. Felices M, Berg LJ. The TEC kinases Itk and Rlk regulate NKT cell maturation, cytokine production, and survival. J Immunol. 2008;180(5): 3007-3018.

65. Huck K, Feyen O, Niehues T, et al. Girls homozygous for an IL-2inducible $\mathrm{T}$ cell kinase mutation that leads to protein deficiency develop fatal EBV-associated lymphoproliferation. J Clin Invest. 2009;119(5): $1350-1358$

66. Zhang Q, Davis JC, Lamborn IT, et al. Combined immunodeficiency associated with DOCK8 mutations. $N$ Engl J Med. 2009;361(21): 2046-2055.

67. Sullivan KE. DiGeorge syndrome and chromosome 22q11.2 deletion syndrome. In: Immunologic Disorders in Infants and Children, 5 th ed. Ochs HD, Stiehm ER, Winkelstein JA, editors. Philadelphia, PA: Elsevier; 2004:523.

68. Roifman CM, Gu Y, Cohen A. Mutations in the RNA component of RNase mitochondrial RNA processing might cause Omenn syndrome. J Allergy Clin Immunol. 2006;117(4):897-903.

69. Borzutzky A, Crompton B, Bergmann AK, et al. Reversible severe combined immunodeficiency phenotype secondary to a mutation of the proton-coupled folate transporter. Clin Immunol. 2009;133(3):287-294.

70. Touzot F, Gaillard L, Vasquez N, et al. Heterogeneous telomere defects in patients with severe forms of dyskeratosis congenita. J Allergy Clin Immunol. 2012;129(2):473-482.

71. Blaese RM, Culver KW, Miller AD, et al. T lymphocyte-directed gene therapy for ADA-SCID: Initial trial results after 4 years. Science. 1995;270(5235):475-480.

72. Ferrua F, Brigida I, Aiuti A. Update on gene therapy for adenosine deaminase-deficient severe combined immunodeficiency. Curr Opin Allergy Clin Immunol. 2010;10(6):551-556.

73. Hacein-Bey-Abina S, Fischer A, Cavazzana-Calvo M. Gene therapy of X-linked severe combined immunodeficiency. Int $J$ Hematol. 2002;76(4):295-298.

74. Hacein-Bey-Abina S, Hauer J, Lim A, et al. Efficacy of gene therapy for X-linked severe combined immunodeficiency. $N$ Engl J Med. 2010;363(4):355-364

75. Zhou S, Mody D, Deravin SS, et al. A self-inactivating lentiviral vector for SCID-X1 gene therapy that does not activate LMO2 expression in human T cells. Blood. 2010;116(6):900-908.

76. Montini E, Cesana D, Schmidt M, et al. The genotoxic potential of retroviral vectors is strongly modulated by vector design and integration site selection in a mouse model of HSC gene therapy. J Clin Invest. 2009;119:964-975.

77. Cartier N, Hacein-Bey-Abina S, Bartholomae CC, et al. Hematopoietic stem cell gene therapy with a lentiviral vector in X-linked adrenoleukodystrophy. Science. 2009;326:818-823.

78. Perez EE, Wang J, Miller JC, et al. Establishment of HIV-1 resistance in $\mathrm{CD} 4+\mathrm{T}$ cells by genome editing using zinc-finger nucleases. Nat Biotechnol. 2008;26:808-816.

79. Silva G, Poirot L, Galetto R, et al. Meganucleases and other tools for targeted genome engineering: Perspectives and challenges for gene therapy. Curr Gene Ther. 2011;11(1):11-27.

80. Liston A, Enders A, Siggs OM. Unravelling the association of partial T-cell immunodeficiency and immune dysregulation. Nat Rev Immunol. 2008;8:546 


\section{Publish your work in this journal}

The Application of Clinical Genetics is an international, peer-reviewed open access journal that welcomes laboratory and clinical findings in the field of human genetics. Specific topics include: Population genetics; Functional genetics; Natural history of genetic disease; Management of genetic disease; Mechanisms of genetic disease; Counselling and

ethical issues; Animal models; Pharmacogenetics; Prenatal diagnosis; Dysmorphology. The manuscript management system is completely online and includes a very quick and fair peer-review system, which is all easy to use. Visit http://www.dovepress.com/testimonials.php to read real quotes from published authors.

Submit your manuscript here: http://www.dovepress.com/the-application-of-clinical-genetics-journal 